\title{
An Unusual Presentation of Fungal Mass in Concha Bullosa
}

\author{
Ganesh Kumar Balasubramaniam, Ramanathan Thirunavukarasu, \\ Ramesh Babu Kalyanasundaram, Gitanjali Narendran \\ Department of ENT, Thanjavur Medical College, Thanjavur, India \\ Email: drganeshkumarb@gmail.com
}

Received 22 June 2014; revised 21 July 2014; accepted 20 August 2014

Copyright (C) 2014 by authors and Scientific Research Publishing Inc.

This work is licensed under the Creative Commons Attribution International License (CC BY). http://creativecommons.org/licenses/by/4.0/

(c) () Open Access

\begin{abstract}
Fungal infection usually involves the paranasal sinuses. This is a rare case of fungal mass in concha bullosa. A 19-year-old immunocompetent female patient presented with nasal obstruction. Anterior rhinoscopy revealed enlarged middle turbinate on left side. CT showed heterogenous opacity and enlargement of left middle turbinate. Intraoperatively, middle turbinate was found to be filled with cheesy material which was culture positive for Aspergillus fumigatus.
\end{abstract}

\section{Keywords}

Concha Bullosa, Fungal Ball, Fungal Sinusitis, Nasal Obstruction, Aspergillus

\section{Introduction}

Concha bullosa is a common anatomical variation of lateral nasal wall. The incidence of concha bullosa in various studies is $14 \%$ to $53.6 \%$ [1]. The most common content is air. Fungal mass in concha bullosa is a very rare condition with only 4 cases documented so far. Mahmut Ozkiris et al. reported a case of a 55-year-old woman with fungal ball in concha bullosa presenting with anosmia [2]. Ciger et al. reported the presence of a dark brown fungal ball during endoscopic resection of concha bullosa in a 29-year-old woman [3]. We present one such case of a young female patient with an isolated fungal mass in the left middle concha without any evidence of fungal infection of paranasal sinuses.

\section{Case Report}

A 19-year-old female patient presented with complaints of bilateral nasal obstruction (left > right) for the past 1 year, with reduced sense of smell. There was no history of recurrent sneezing or chronic headache. There was no history of previous surgery or trauma to nose. Anterior rhinoscopy revealed an enlarged left middle turbinate

How to cite this paper: Balasubramaniam, G.K., Thirunavukarasu, R., Kalyanasundaram, R.B. and Narendran, G. (2014) An Unusual Presentation of Fungal Mass in Concha Bullosa. International Journal of Otolaryngology and Head \& Neck Surgery, 3, 263-266. http://dx.doi.org/10.4236/ijohns.2014.35048 
with septal deviation to right side and septal spur on right side. Examination of paranasal sinuses revealed mild tenderness during palpation in left ethmoid sinuses. CT paranasal sinuses showed heterogenous opacity of enlarged left middle turbinate in anterior cuts with concha bullosa in posterior cuts and septal deviation to right side (Figure 1). There was opacity involving anterior group of ethmoid sinuses on left side. A differential diagnosis of mucocele/fungal mass/tumor was made. The patient was taken up for surgery. Under local anaesthesia, after submucosal resection and spurrectomy, the middle turbinate was incised. It was found to be filled with cheesy material which was removed (Figure 2) and sent for microscopy and culture. Anterior ethmoidectomy was done on left side. Post operative period was uneventful. Microscopy revealed the presence of fungal hyphae. The culture of the material was positive for Aspergillus fumigatus. The patient did not show any evidence of recurrence during follow-up (Figure 3).

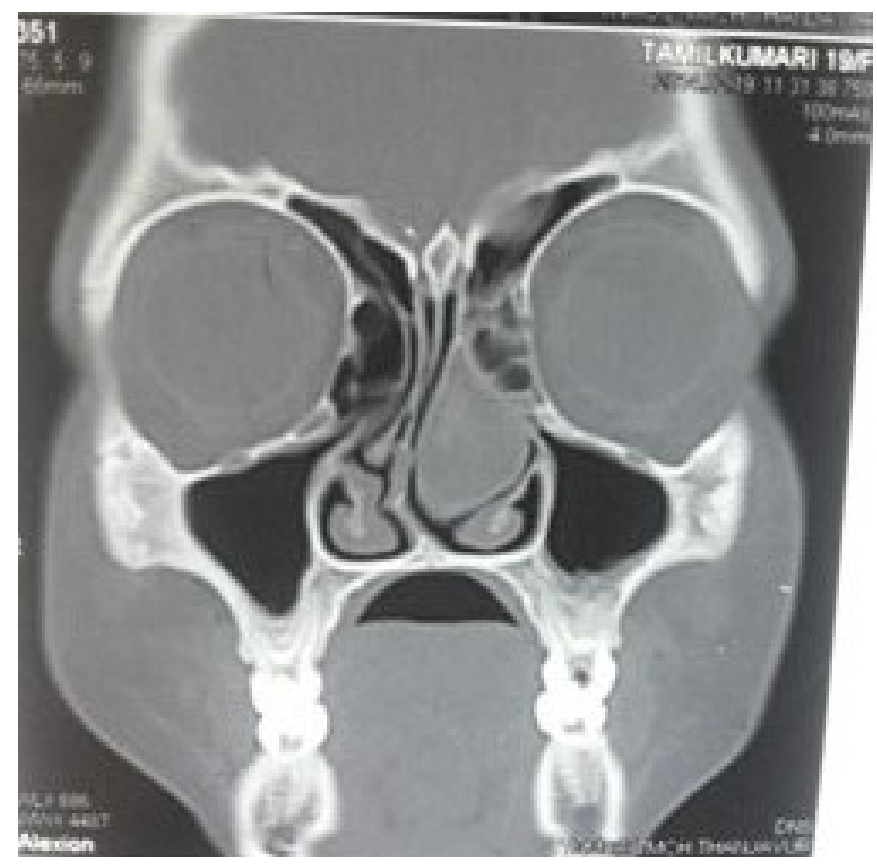

Figure 1. Preoperative CT of patient showing opacity and enlargement involving left concha with septal deviation to right.

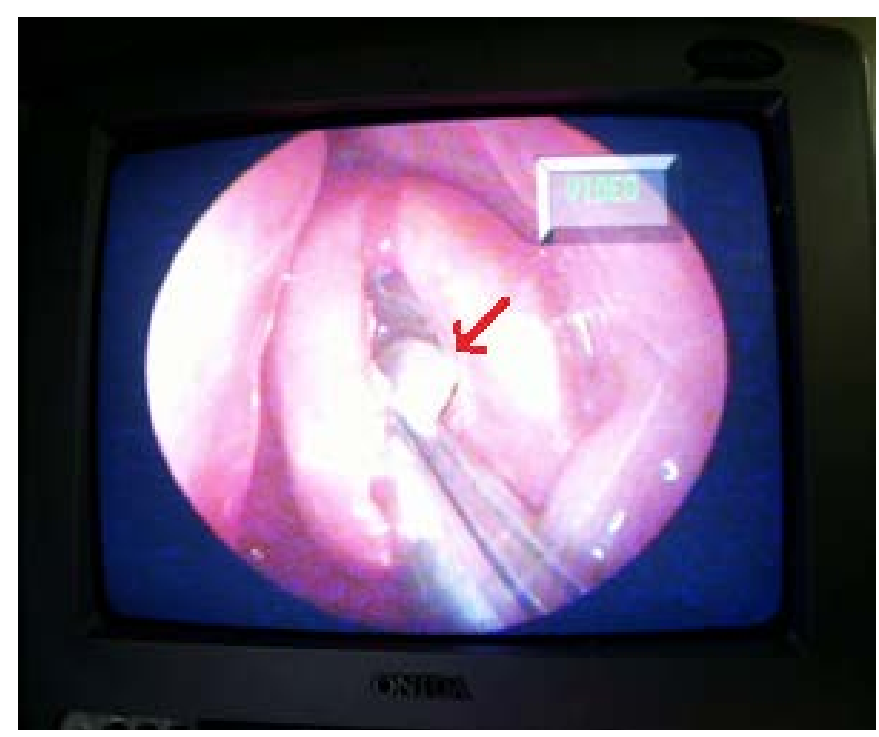

Figure 2. Cheesy fungal material in concha. 


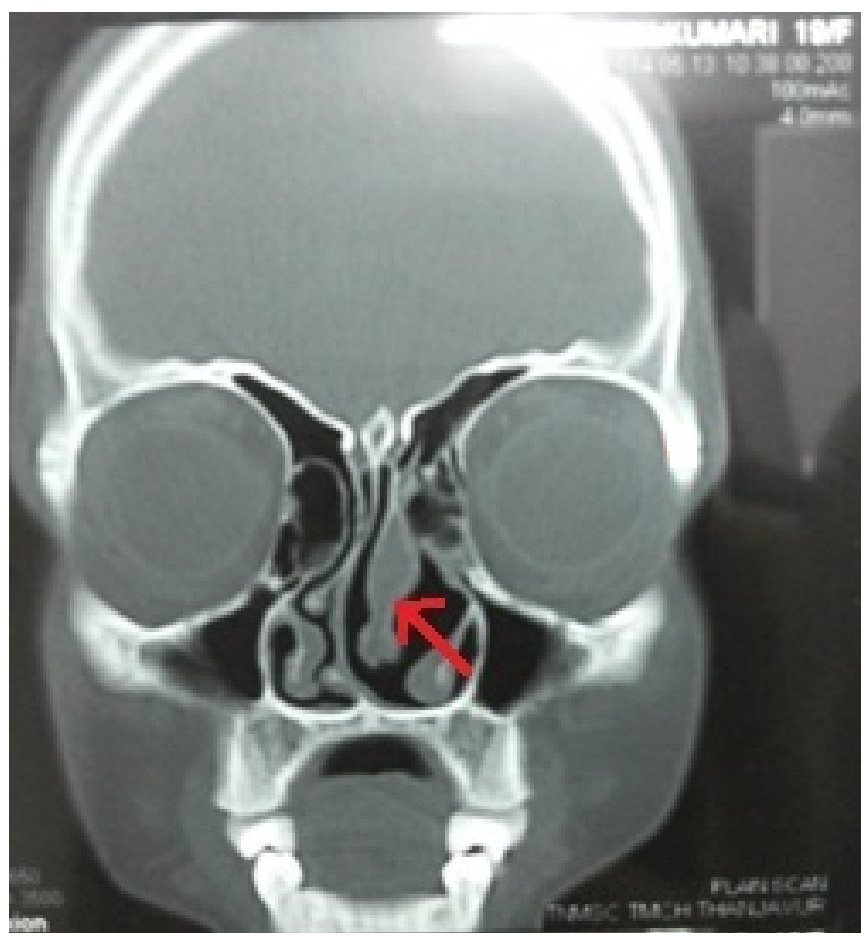

Figure 3. Postoperative CT after removal of fungal mass from left middle turbinate.

\section{Discussion}

Concha bullosa is pneumatisation and enlargement of turbinates. It is most commonly seen in middle turbinate. It is pneumatised from frontal recess, agger nasi cell, anterior ethmoid air cells or middle meatus [4]. There are three types of concha bullosa based on specific site of pneumatisation: 1) Lamellar type: vertical lamella is pneumatised. 2) Bulbous type: inferior portion of turbinate is pneumatised. 3) Extensive (large) type: vertical lamella plus inferior portion of the turbinate is pneumatised [5]. Concha bullosa of superior and inferior turbinates and even bilateral concha bullosa of all the three turbinates have been reported. The concha bullosa can be asymptomatic or cause headache, pain between the eyes, nasal obstruction or obstruct sinus ostium causing symptoms of sinusitis. Though the most common content is air, rarely purulent material, bony septum, pyocele, ossifying fibroma, fungal mass and cholesteatoma have been found inside [6].

Fungal infection of nose and paranasal sinuses can cause Allergic fungal rhinosinusitis, Acute or chronic invasive fungal rhinosinusitis or fungal ball. All of the above conditions are seen in immunocompetent individuals except acute invasive fungal sinusitis which is seen in immunocompromised individuals [7]. Fungal ball is most commonly seen in the maxillary sinus followed by sphenoid and ethmoid sinuses. It is usually seen in elderly patients (around 60 years) with a female preponderance. Common causative fungi are Aspergillus fumigatus followed by Aspergillus flavus, Scedosporium, Pseudoallescheria boydii and Alternaria. The disease is seen in humid coastal areas. Fungal balls follow a slow benign course. Symptoms include nasal obstruction, nasal discharge, cacosmia, and facial pain. Rarely there may be epistaxis, visual disturbances, fever and convulsions. CT shows heterogenous opacity in the involved sinus with thickening of sinus walls and rarely calcification. Microscopic examination using Haematoxylin and Eosin or Gomori methenamine silver is useful. The fungal mass consists of dense tangles of hyphae with calcifications and oxalate crystals. The fungus can be cultured on Sabouraud's dextrose agar with antibiotics without cycloheximide at $25^{\circ} \mathrm{C}$ and $37^{\circ} \mathrm{C}$. Cultures are positive in only $20 \%$ to $50 \%$ of cases due to lack of viability of fungus [7]. PCR is sensitive to detect viable and nonviable fungal pathogens. A differential diagnosis includes bacterial sinusitis, mucocele, pyocele, malignant tumor or metastasis [8]. It is treated by surgical removal of fungal mass and widening of the sinus ostium. Intraoperatively the gross appearance of the fungus is gritty or cheesy and clay like. The colour may vary white, yellow, green, brown or black. Recurrence is uncommon after debridement and antifungals are not required [8]. 
This patient is a young patient (in contrast to the usual age incidence around 60 years). The possible etiology could be some unrecognised minor trauma or the fungal spores could have entered via the drainage pathway of the concha and got lodged inside the concha. The cause of reduced sense of smell could be mechanical obstruction from enlarged turbinate or damage to olfactory epithelium from chronic inflammation due to sinusitis. Post operatively patient had relief of symptoms and there was no evidence of recurrence.

\section{Conclusions}

- Isolated fungal mass in concha bullosa is a rare condition.

- In case of enlarged middle turbinate with heterogenous opacity with calcifications a diagnosis of fungal mass should be considered.

- Diagnosis is confirmed by microscopy or culture.

- Surgical debridement with conchoplasty is the mainstay of treatment.

\section{References}

[1] Zinreich, S., Albayram, S., Benson, M. and Oliverio, P. (2003) The Ostiomeatal Complex and Functional Endoscopic Surgery in Head and Neck Imaging. 4th Edition, Mosby, St. Louis, 149-173.

[2] Ozkiris, M., Kapusuz, Z., Seckin, S. and Saydam, L. (2013) Fungus Ball in Concha Bullosa: A Rare Case with Anosmia. Case Reports in Otolaryngology, 2013, Article ID: 920406.

[3] Ciger, E., Demiray, U., Onal, K. and Songu, M. (2012) An Unusual Location for a Fungus Ball: The Concha Bullosa. The Journal of Layngology and Otology, 126, 844-846.

[4] Bradoo, R. (2012) Anatomical Principles of Endoscopic Sinus Surgery A Step by Step Approach. Jaypee, NewDelhi, 93-94.

[5] Bolger, W.E. and Butzin, C.A. (1991) Parsons Paranasal Sinus Bony Anatomic Variations and Mucosal Abnormalities. CT Analysis for Endoscopic Sinus Surgery. Laryngoscope, 101, 56-64. http://dx.doi.org/10.1288/00005537-199101000-00010

[6] Cukurova, I., Demirhan, E., Karaman, Y. and Yigitbasi, O.G. (2009) Extraordinary Pathologic Entities within the Concha Bullosa. Saudi Medical Journal, 30, 937-941.

[7] (2008) Scott-Brown's Otorhinolaryngology, Head and Neck Surgery. 7th Edition, Vol. 2, Hodder Education, London, $1449-1452$.

[8] Dufour, X., Lacroix, K.C., Ferrie, J.C., Goujon, J.M., Rodier, M.H. and Klossek, J.M. (2006) Paranasal Sinus Fungus Ball: Epidemiology, Clinical Features and Diagnosis. A Retrospective Analysis of 173 Cases. Medical Mycology, 44, 61-67. http://dx.doi.org/10.1080/13693780500235728 
Scientific Research Publishing (SCIRP) is one of the largest Open Access journal publishers. It is currently publishing more than 200 open access, online, peer-reviewed journals covering a wide range of academic disciplines. SCIRP serves the worldwide academic communities and contributes to the progress and application of science with its publication.

Other selected journals from SCIRP are listed as below. Submit your manuscript to us via either submit@scirp.org or Online Submission Portal.
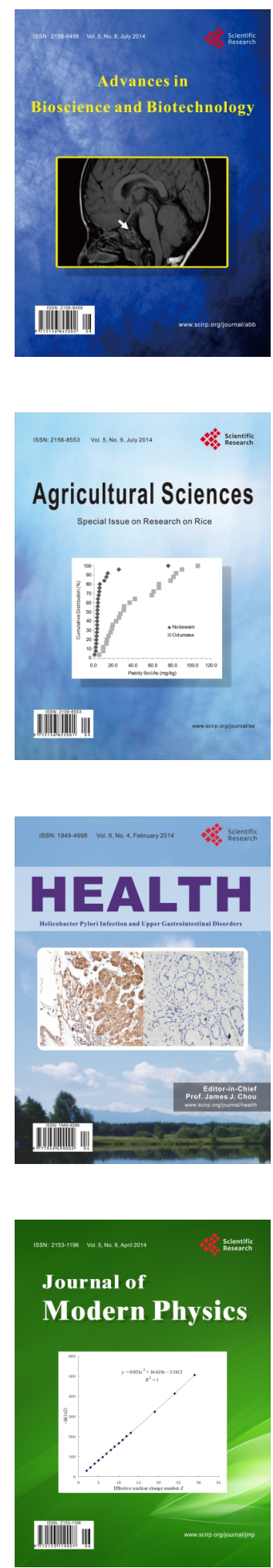
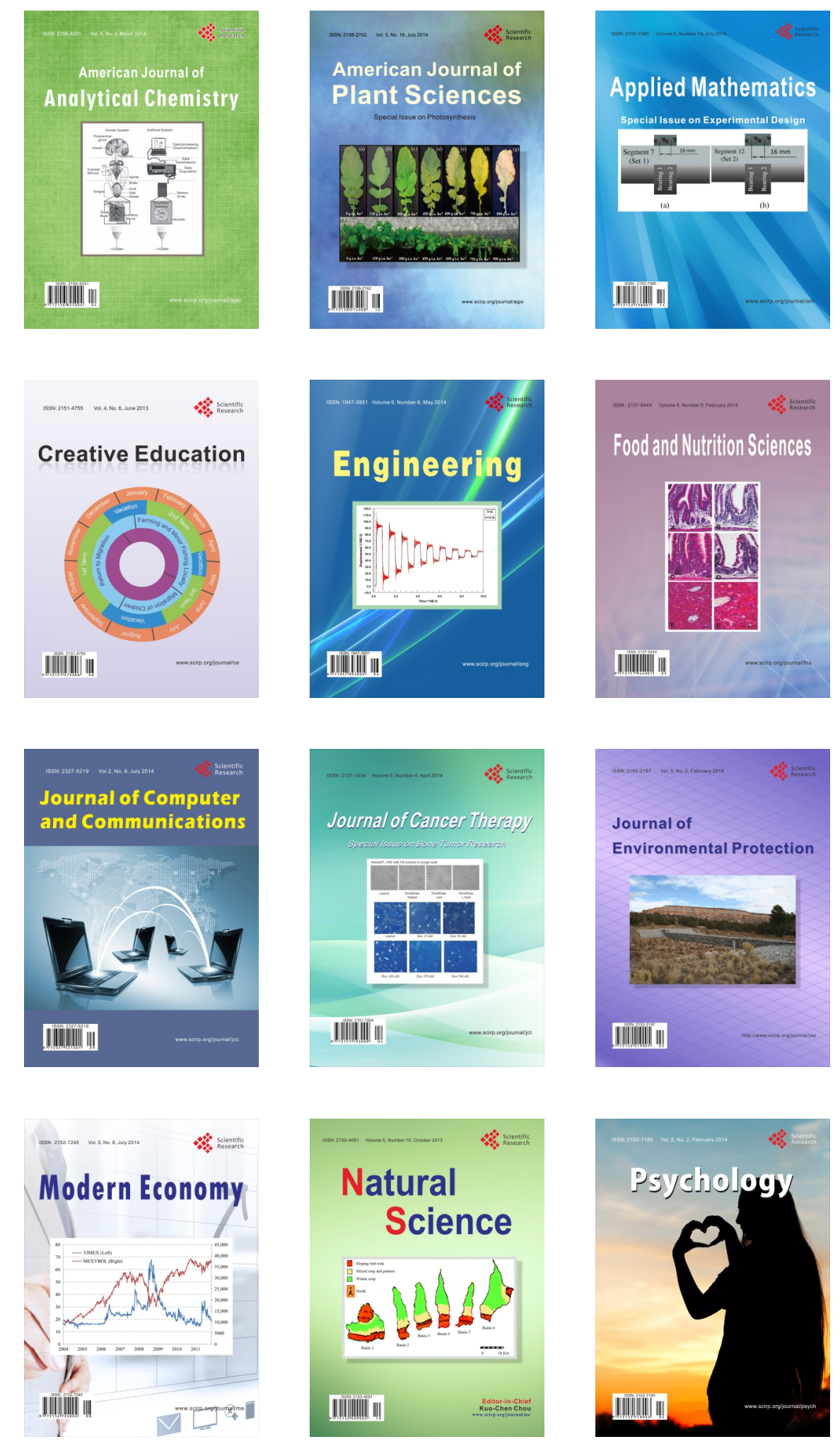